\title{
Estudo de Caso Sobre o Perfil das Estruturas de Capital e Rentabilidade de Indústrias Brasileiras
}

\author{
Antonio Francisco de A. Silva Junior (ITA) antonio.francisco@bcb.gov.br \\ Luis Fernando Teixeira de Camargo (ITA) luis@camargo.srv.br \\ Paula Lavorato Loures (ITA) ploures@mec.ita.br \\ Ricardo Zöllner Holmo (ITA) ricardoholmo@uol.com.br \\ Arnoldo Souza Cabral (ITA) cabral@mec.ita.br
}

\section{Resumo}

Este trabalho apresenta uma análise do perfil de endividamento e da rentabilidade por subsetores da indústria brasileira, buscando verificar se existe uma relação entre esses indices. Foi realizada uma análise de regressão linear com dados desses dois indicadores, utilizando informações financeiras para a indústria, com 78 sub-setores, divulgados pelo "Balanço Anual da Gazeta Mercantil, julho de 2002 - ano XXVI - n. 26". Os resultados apontam na direção de uma relação inversa entre a rentabilidade e o nível de endividamento das empresas, com um nível de confiaça superior a 95\%.

A análise de regressão revelou também que não existe relação entre o tamanho da empresa e o nivel de endividamento, contrariando a idéia de que empresas maiores por terem maior facilidade de acesso ao crédito tenderiam a se endividar mais. Finalmente, em função dos dados de rentabilidade e endividamento foram identificados os setores que teriam maior possibilidade de crescimento no curto prazo, em função da disponibilidade de captação de recursos desses setores.

Palavras chave: Estrutura de Capital, Alavancagem, Endividamento.

\section{Introdução}

Este trabalho tem como objetivo realizar um estudo de caso comparando os perfis da estrutura de capital de indústrias de diferentes sub-setores, com o intuito de verificar a existência e o sinal da relação entre o nível de endividamento e o retorno da empresa. Assim, é feita uma análise estatística da estrutura de capital comparativamente aos níveis de rentabilidade de cada sub-setor.

A teoria sobre estrutura de capital indicaria que um certo grau de endividamento, ou alavancagem financeira, seria estimulado pelos incentivos fiscais. No entanto, conforme abordado por Procianoy e Schmitt (1995), haveria uma taxa de juros de equilíbrio no mercado, acima da qual os benefícios fiscais não compensariam o endividamento. O problema é que não existe uma fórmula geral para o cálculo do nível ótimo de endividamento. Assim, as empresas optam pelo nível de alavancagem em função de outros fatores além dos incentivos fiscais, tais como: valor das taxas de juros, orientações estratégicas, restrições de acesso ao crédito, grau de aversão ao risco etc. Desta forma, a pesquisa realizada neste trabalho discute de forma empírica a existência de um nível ótimo de endividamento. Este nível ótimo de endividamento não é medido aqui em termos do custo de capital, conforme abordagem seguida por Famá et alli (2001), que analisaram empiricamente os trabalhos de Modigliani e Miller de 1958 e de 1963. Nesta pesquisa, parte-se do pressuposto de que os outros fatores, que não os incentivos fiscais, que determinam a escolha do nível de endividamento de uma empresa, influem na rentabilidade da mesma.

Os testes empíricos deste trabalho foram realizados partindo de uma amostra contendo os 
dados financeiros de 21 setores industriais e dos seus 78 sub-setores ${ }^{1}$, que foram divulgados pelo "Balanço Anual da Gazeta Mercantil, julho de 2002 - ano XXVI - n. 26". A partir das informações disponibilizadas foram calculados o ROI (retorno sobre investimento), ou seja, lucro líquido dividido pelo ativo total, e o índice de endividamento geral (IE), que é definido como a relação: (ativo total - patrimônio líquido)/ patrimônio líquido.

Em um primeiro momento, este trabalho investigou o nível de alavancagem média dos diversos sub-setores, procurando identificar a existência ou não de algum padrão no perfil de endividamento. Em seguida, foi feita uma análise de regressão linear para verificar a hipótese nula de existência de uma relação entre rentabilidade e nível de endividamento. Além disso, procurou-se identificar, por meio de regressões, se empresas de maior porte (maior ativo total) apresentavam níveis diferenciados de endividamento, já que, pelo menos em tese, apresentariam maior facilidade de acesso a crédito. Finalmente, foi identificada a capacidade de crescimento no curto prazo dos setores e sub-setores industriais. Esta última análise foi implementada associando o nível de endividamento e de rentabilidade conjuntamente, já que empresas com baixo grau de endividamento e alta rentabilidade em um período apresentam, a princípio, possibilidade de maior acesso a crédito e utilização de recursos próprios, ou seja, maior capacidade de investimento.

\section{Fundamentação Teórica}

A combinação de diversas alternativas de capital de terceiros e capital próprio por uma empresa é conhecida como estrutura de capital ou estrutura financeira. Esta combinação, que está associada ao conceito de custo de capital, é usada pelas empresas para financiar suas atividades de investimento através das proporções relativas da dívida de curto prazo, dívida de longo prazo e capital próprio. No uso de recursos de terceiros, a alavancagem financeira é uma poderosa ferramenta que tem como finalidade alterar a relação risco e retorno da firma.

Normalmente, uma empresa pode optar por qualquer estrutura de capital que deseje utilizando instrumentos financeiros como emissão de ações preferenciais, warrants, debêntures conversíveis entre outros. Além disso, as operações de leasing, swaps de taxa de juros e contratos a termo, permitem alterar as características desses instrumentos. Como são grandes as alternativas de investimentos, as variações de estrutura de capital são infinitas (Ross et alli, 1995).

A importância na determinação da melhor estrutura de capital, escolhendo a proporção ideal de capital de terceiros (dívidas de curto e longo prazos) e de capital próprio, está associada à busca da maximização do valor da empresa. Para Ross et alli (1995), as teorias da estrutura de capital se encontram entre as mais sofisticadas na área de finanças. Para Gitman (1997), a estrutura de capital é uma das áreas mais complexas na tomada de decisão financeira. Dessa forma, para atingir o objetivo da empresa, a maximização da riqueza dos proprietários, o administrador financeiro deve ser capaz de avaliar a estrutura de capital da empresa e entender seu relacionamento com o risco, o retorno e o valor, em particular à busca da estrutura ótima de capital da empresa.

Famá e Grava (2000) realizaram uma análise histórica sobre a teoria da estrutura de capital dividindo o pensamento neste campo em três fases distintas. Na primeira fase, que vai até a década de 50, a noção de risco não dispunha de um ferramental adequado para cálculo e o instrumental utilizado era basicamente determinístico. A segunda fase teve início com o trabalho de Markowitz (1952), que é considerado um marco na teoria de finanças, e,

\footnotetext{
${ }^{1}$ Foram eliminados alguns sub-setores na análise, pois esses foram classificados como diversos na base de dados. Além disso, foram eliminados da amostra quatro registros que apresentavam informações claramente não consistentes.
} 
particularmente, para a estrutura de capital os trabalhos de Modigliani e Miller (1958 e 1963) foram fundamentais. A terceira fase, chamada de comportamental por Famá e Grava, desenvolve-se em paralelo com a segunda fase e preocupa-se com a teoria de agência ${ }^{2}$, onde a estrutura ótima de capital seria aquela que minimizaria o custo de agência total.

De fato, o estudo da estrutura de capitais das empresas foi bastante influenciado pelos trabalhos de Modigliani e Miller. Na ausência de impostos, esses autores afirmam que o valor da empresa independe da estrutura de capital, ou seja, não há uma estrutura de capital melhor ou pior para os acionistas da empresa. Assim, o retorno esperado do capital próprio é diretamente associado ao endividamento em função da elevação do nível de risco. Considerando o custo médio ponderado de capital da empresa $r_{P}$ :

$r_{P}=\frac{B}{B+S} \cdot r_{B}+\frac{S}{B+S} \cdot r_{S}$

onde, $r_{B}$ é o custo de capital de terceiros; $r_{S}$ é o custo do capital próprio; $B$ é o valor do endividamento; e $S$ é o valor das ações da empresa ou o capital próprio. A hipótese de que o custo médio ponderado de capital da empresa independe da estrutura de capital leva à seguinte expressão para o custo do capital próprio, ou retorno esperado:

$r_{S}=r_{0}+\frac{B}{S} \cdot\left(r_{0}-r_{B}\right)$

onde $r_{0}$ é o custo de capital de uma empresa sem capital de terceiros. As expressões acima não consideram os incentivos fiscais ao endividamento (dedução do pagamento de juros da base de cálculo de incidência do IR pessoa jurídica) e não considera os impostos incidentes nos recebimentos de juros e de dividendos. Ross et alli (1995) discutem a seguinte expressão para o valor da empresa alavancada considerando esses impostos:

$V_{L}=V_{U}+\left[1-\frac{\left(1-T_{C}\right) \cdot\left(1-T_{S}\right)}{\left(1-T_{B}\right)}\right] \cdot B$

onde, $V_{L}$ é o valor da empresa alavancada; $V_{U}$ é o valor da empresa sem dívidas; $T_{C}$ é a alíquota de imposto de renda pessoa jurídica; $T_{B}$ é a alíquota do imposto de renda pessoa física que incide sobre rendimentos ordinários; e $T_{S}$ é a alíquota de imposto de renda pessoa física que incide sobre distribuições a acionistas. De acordo com Procianoy e Schmitt (1995), a expressão acima sugeriria a existência de uma taxa de juros de equilíbrio no mercado. Acima dessa taxa de equilíbrio, tornam-se desinteressantes os benefícios fiscais da dívida e abaixo da mesma o endividamento seria estimulado. Os autores destacam ainda que muitos trabalhos buscaram desenvolver modelos de estrutura de capital considerando a relação entre o valor dos benefícios fiscais proporcionados pela dívida e os custos de inadimplência.

Em Myers e Maluf (1984) foram analisadas duas estratégias de endividamento. A primeira seria a opção estática entre dívida e capital próprios e a segunda o modelo dinâmico chamado de Pecking Order. Na primeira estratégia, as empresas estabelecem um objetivo de endividamento e perseguem esse objetivo. Na segunda estratégia, as empresas estabelecem uma ordem de preferência pelas alternativas de financiamento que inicia com a escolha de uso dos lucros retidos, seguida da emissão de dívida nova e, finalmente, emissão de novas ações.

Eid (1996) argumenta que, além dessas duas alternativas de estratégia, uma terceira seria o oportunismo na captação de recursos, isto é, as empresas captam recursos na medida em que

\footnotetext{
${ }^{2}$ De acordo com Famá e Grava (2000), o problema de agência surge toda vez que alguém, chamado de agente, é posto a administrar os interesses de outro, chamado de principal. O custo de agência surge, então, toda vez que um agente não age em conformidade com o objetivo de maximizar a riqueza dos proprietários da empresa.
} 
surgem boas oportunidades de investimento, sem se preocuparem com uma hierarquia de preferência ou um objetivo de endividamento. O autor concluiu que, no Brasil, a hipótese de manutenção de uma relação fixa entre os montantes de capitais próprios e de terceiros pela empresa, tendo em vista uma minimização do custo médio de capital, não é adotada pela maioria das empresas no país. As alternativas de aproveitamento de oportunidades de mercado e a manutenção de uma hierarquia de captação predeterminada são as opções preferidas pelas empresas nacionais. Além disso, o trabalho de Eid sugere também que as empresas brasileiras, apesar das taxas de juros elevadas, preferem os empréstimos bancários como primeira fonte de financiamento, seguida da emissão de ações ordinárias, aparecendo como última alternativa o uso de lucros retidos. Essa constatação estaria se contrapondo às proposições de Myers e Maluf (1984). Eid argumenta que a existência de fontes de financiamento subsidiadas e a possibilidade de pouca utilização de lucros retidos, já que a lucratividade das empresas não é alta, explica os resultados encontrados para o Brasil.

De acordo com De Angelo e Masulis (1980) outros benefícios fiscais, depreciação, prejuízos acumulados, compensações etc. levariam à existência de uma estrutura de capital ótima característica de cada empresa. Por outro lado, os trabalhos de Modigliani e Miller citados anteriormente, indicam uma estrutura de capital ótima para a economia como um todo. Famá e Grava (2000) destacam, no entanto, que na visão tradicional o efeito de criação de valor ocorre apenas para alavancagens moderadas, sendo, no entanto, suplantado por uma alta nos custos da dívida e capital acionário quando a alavancagem se torna elevada.

Titmam e Wessels (1988), após estudos empíricos, mostraram que empresas com um único produto têm baixa relação de endividamento. Segundo esses autores, firmas pequenas tendem a usar mais capital de curto prazo do que firmas grandes e não há evidências que apóiem os trabalhos teóricos que indicam que níveis de endividamento estariam relacionados ao crescimento esperado da firma, ou à volatilidade. Por outro lado, esses autores encontraram evidências de que empresas mais lucrativas têm menor endividamento.

A partir desta revisão teórica, este trabalho investigará a hipótese nula de existência de uma relação entre rentabilidade e nível de endividamento. A idéia básica é de que a estrutura de capital adotada pelas empresas varia de acordo com suas peculiaridades, orientação estratégica, acesso a crédito, aversão a risco etc. O aumento do nível de endividamento não necessariamente conduzirá a uma redução do custo médio ponderado do capital. Caso a empresa esteja com elevado nível de endividamento, por exemplo, o custo do crédito se eleva em função do risco de inadimplência.

O modelo do CAPM (Capital Asset Pricing Model) descreve uma relação entre risco e retorno para todos os ativos pela seguinte relação:

$$
E\left(R_{i}\right)=R_{f}+\left\lfloor E\left(R_{M}\right)-R_{f}\right\rfloor \cdot \beta
$$

onde $E\left(R_{i}\right)$ é o retorno esperado de cada ativo, $R_{f}$ é o retorno do ativo livre de risco, $E\left(R_{M}\right)$ corresponde ao retorno esperado da carteira de mercado e $\beta$ é a medida do risco sistemático, ou seja, quanto maior o seu valor, maior o nível de risco associado ao ativo e maior o retorno esperado do ativo. $\mathrm{O} \beta$ da carteira de mercado é igual a um. Dessa forma, um ativo que tem um $\beta$ maior do que um apresentará um retorno superior ao retorno da carteira de mercado, se este último for positivo. No caso de um retorno negativo da carteira de mercado, um ativo com $\beta$ maior que um apresentará um retorno menor que o de mercado, ou seja, mais negativo ainda. 


\section{Análise dos Resultados}

Dos 78 sub-setores analisados o índice de endividamento médio foi de 1,4, com um desvio padrão de 0,83. A um nível de confiança de 90\%, nenhum sub-setor apresentou endividamento abaixo da média. Em contrapartida, seis sub-setores apresentaram endividamento superior à média: equipamentos de telecomunicações, metais preciosos, fiação-tecelagem e confecção, linha branca, artigos de vestuário e artefatos de papel, que representam $4 \%$ do total dos ativos do universo investigado. Utilizando os dados da revista "América - Economia", de 1997, que catalogou informações financeiras das 500 maiores empresas em faturamento líquido da América Latina, em 1995, Famá e Melher (1999) encontraram um valor médio de endividamento de 0,97 para as empresas brasileiras de maior lucro e 1,92 para as empresas com maior prejuízo nominal. A partir das informações disponibilizadas no artigo desses autores, foi encontrado um endividamento médio de 1,6 para trinta e nove indústrias brasileiras. Esse resultado é muito próximo do valor de 1,4 encontrado neste trabalho, o que revela não ter havido uma mudança substancial entre os valores médios de endividamento nos anos de 1995 e 2002 . O fato do valor médio desse índice ser superior a um corrobora a observação de Eid (1996) de que as indústrias brasileiras, na média, utilizam mais capital de terceiros do que recursos próprios o que pode ser justificado pela sua baixa lucratividade, ou também pelos incentivos fiscais de acordo com a discussão apresentada anteriormente.

Os 10 sub-setores industriais que apresentaram menor $\mathrm{ROI}^{3}$ em 2002 tiveram um nível de endividamento de 2,2 (com desvio padrão de 1,1), enquanto os 10 sub-setores industriais com maior ROI tiveram um IE de 1,3 (com desvio padrão de 0,7). Famá e Melher (1999), utilizando os dados descritos acima, encontraram resultados similares, com as 50 empresas de maiores prejuízos na América Latina apresentando, em média aritmética simples, um quociente de endividamento 2,13 enquanto que as 50 empresas de maiores lucros apresentaram endividamento médio de 0,82 . Assim, embora os resultados encontrados não permitam uma conclusão precisa, do ponto de vista estatístico, tendo em vista os desvios padrões, pode-se afirmar que existem indícios de que quanto maior o nível de endividamento menor o retorno esperado. Para investigar essa relação, para as indústrias brasileiras, foi realizada uma regressão linear entre as variáveis ROI x IE:

$R O I=\alpha_{1}+\alpha_{2} \cdot I E+\varepsilon$

onde, $\alpha_{1}$ e $\alpha_{2}$ são os coeficientes da regressão e $\varepsilon$ é o termo aleatório. Vale destacar que o objetivo da regressão não é explicar o retorno apenas com a informação do nível de endividamento, já que diversas outras variáveis influem no ROI. Dessa forma, não são esperados, a princípio, elevados valores de R-Quadrado (grau de explicação do modelo, que no máximo será igual a 1) com a regressão. $O$ que se procura identificar com a regressão é avaliar se existe alguma relação entre o ROI e o IE, ou seja, a hipótese nula de que $\alpha_{2} \neq 0$. A um nível de significância de $95 \%$, a hipótese nula é aceita se a estatística $t$ de Student, em valor absoluto, for superior a 1,96. O sinal de $\alpha_{2}$ positivo indica que a rentabilidade aumenta com o valor do índice de endividamento, o contrário ocorre se o coeficiente for negativo. $\mathrm{O}$ resultado da regressão é apresentado nas tabelas e figura abaixo:

\footnotetext{
${ }^{3}$ Resultados similares foram obtidos usando a rentabilidade medida pelo lucro líquido sobre patrimônio líquido no lugar do ROI.
} 


\begin{tabular}{lcc}
\hline Item & Valor & Estatística t \\
\hline Interseção & 0,0725 & 5,70 \\
Inclinação & $-0,0347$ & $-4,42$ \\
\hline
\end{tabular}

Fonte: (Elaboração própria)

Tabela 1 - Coeficientes da Regressão Linear entre Rentabilidade x Endividamento

\begin{tabular}{lc}
\hline Item & Valor \\
\hline R múltiplo & 0,452 \\
R-Quadrado & 0,204 \\
R-Quadrado ajustado & 0,194 \\
Erro padrão & 0,057 \\
Observações & 78 \\
\hline Fonte: (Elaboração própria) &
\end{tabular}

Tabela 2 - Estatística de Regressão Linear entre Rentabilidade x Endividamento

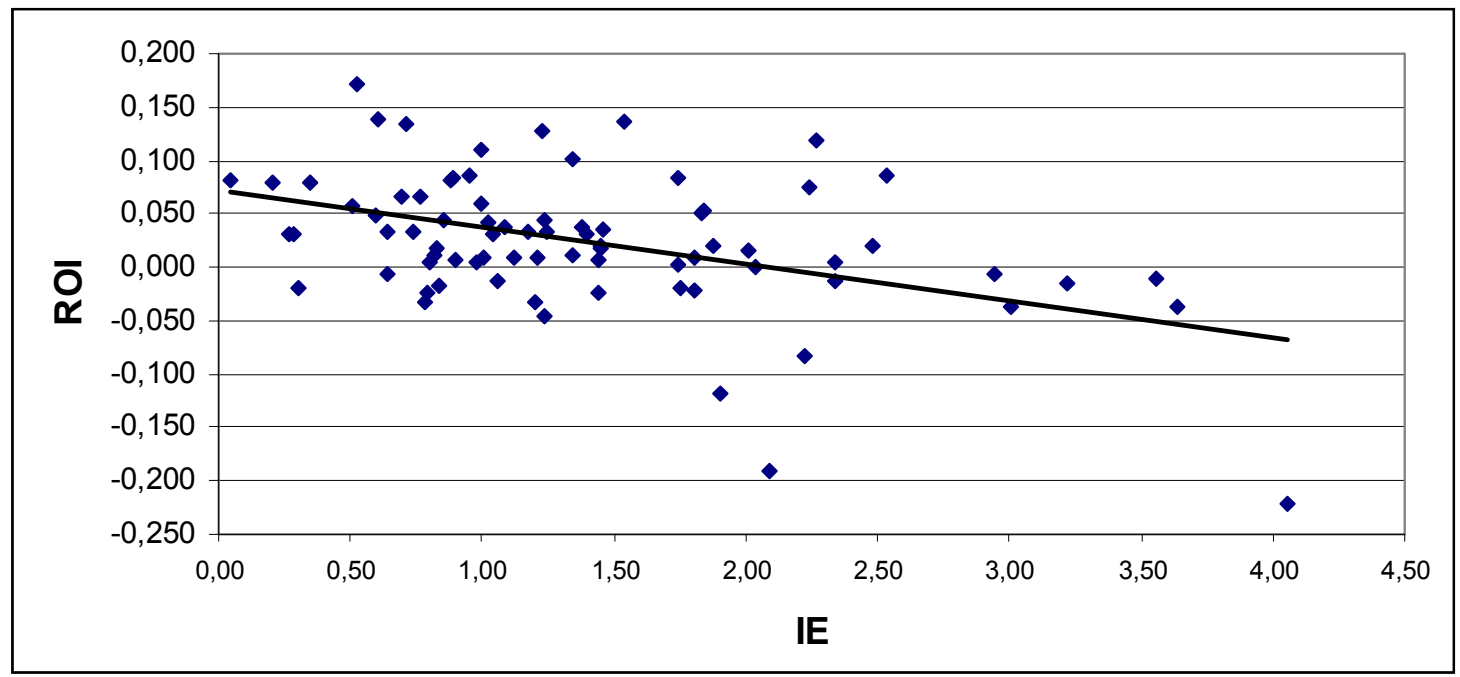

Figura 1 - Retorno x Endividamento

As estatísticas $\mathrm{t}$ revelam que os coeficientes da regressão apresentam elevado nível de significância, enquanto o baixo valor do $\mathrm{R}$ múltiplo revela que, como era de se esperar, existem outros fatores, que não apenas o nível de endividamento, que explicam o comportamento da rentabilidade das empresas.

Os resultados acima indicam que existe uma relação negativa entre o grau de endividamento e a rentabilidade. Um dos dois mecanismos a seguir pode explicar essa relação: i) as empresas com menor índice de endividamento apresentam maior rentabilidade, conclusão encontrada por Titmam e Wessels (1988); ou ii) as empresas com maior índice de endividamento apresentam maior risco e seu retorno seguirá o modelo do CAPM, como a rentabilidade média ponderada pelo ativo de cada subsetor foi menor do que a do ativo livre de risco para o período ${ }^{4}$, considerando a equação (4), que descreve o CAPM, os resultados apresentados

\footnotetext{
${ }^{4}$ Para o ano de 2002, o retorno de uma carteira de mercado, calculado com base no ROI e ponderado pelo volume dos ativos de cada subsetor, foi de $5,2 \%$, contra uma taxa de juros $\left(R_{f}\right)$ ao ano bem superior a esse número.
} 
acima descrevem uma relação entre o nível de endividamento e o risco de um ativo (beta), ou seja, na medida em que o IE cresce o beta aumenta. O segundo mecanismo foi testado por Famá et alli (2001). Esses autores testaram a relação entre o retorno medido pelo CAPM e o índice de endividamento para os setores elétrico e petrolífero, para empresas dos EUA e latino maricanas, com dados de 2000. O trabalho desses autores indicou que em nenhum caso é possível rejeitar (a um nível de confiança de 5\%) a hipótese de que os coeficientes da variável de endividamento são iguais a zero. Assim, esses testes empíricos sugerem o primeiro mecanismo.

Além disso, foi realizada uma regressão linear entre o valor do ativo total de cada sub-setor e o nível de endividamento. Essa análise revelou que não há relação entre o tamanho do ativo da indústria e o seu nível de endividamento, contrariando a idéia de que grandes empresas por terem maior facilidade de acesso ao crédito tenderiam a se endividar mais.

Finalmente, os sub-setores foram reagrupados em setores, segundo os critérios da fonte dos dados e foram identificados os setores com maior possibilidade de crescimento no curto prazo, quais sejam, aqueles que apresentam baixo grau de endividamento e alta rentabilidade no período anterior. A tabela abaixo revela que o setor de material eletrônico demonstra baixa capacidade de crescimento no curto prazo, em função de um alto nível de endividamento e baixa rentabilidade. Este setor engloba o sub-setor de equipamentos de telecomunicações que é o mais significativo em termos de ativo total. Por outro lado, os setores de minerais não metálicos e higiene e limpeza apresentam melhores condições em termos de captação de recursos.

\begin{tabular}{l|r|r}
\hline \multicolumn{1}{c|}{ Setor } & \multicolumn{1}{|c|}{ IE } & \multicolumn{1}{c}{ ROI } \\
\hline MATERIAL ELETRÔNICO & 3,37 & $-0,15$ \\
ELETRODOMÉSTICOS & 1,07 & $-0,04$ \\
PLÁSTICOS & 1,28 & $-0,03$ \\
EQUIPAMENTOS ELÉTRICOS & 2,02 & $-0,01$ \\
TÊXTIL & 1,09 & $-0,01$ \\
MADEIRA E MÓVEIS & 0,89 & 0,00 \\
QUIMICA & 1,59 & 0,01 \\
MECÂNICA & 1,88 & 0,02 \\
AUTOPEÇAS & 1,34 & 0,02 \\
PETROQUIMICA & 1,45 & 0,02 \\
VEICULOS & 2,83 & 0,04 \\
METALURGIA & 1,44 & 0,02 \\
FARMACÊUTICOS & 1,04 & 0,03 \\
MATERIAL DE ESCRITÓRIO & 1,18 & 0,03 \\
PAPEL E CELULOSE & 1,06 & 0,04 \\
BORRACHA & 0,86 & 0,04 \\
COURO E CALÇADOS & 0,78 & 0,05 \\
PETROLEO E GÁS & 1,45 & 0,11 \\
MINERAÇÃO & 0,96 & 0,09 \\
MINERAIS NÃO-METÁLICOS & 0,75 & 0,10 \\
HIGIENE E LIMPEZA & 0,22 & 0,08 \\
\hline
\end{tabular}

Tabela 3 - Endividamento e Rentabilidade dos Setores Industriais

\section{Conclusões}

A estrutura de capital ainda é um tema que requer pesquisas para sua melhor compreensão, sendo um campo de estudos fértil na área de finanças. Este trabalho contribui para revelar que o valor de endividamento médio das indústrias brasileiras, medido pela relação passivo total por patrimônio líquido, foi de 1,4 , com dados financeiros de 2002 , resultado próximo ao 
encontrado com dados de 1995. O fato do valor médio desse índice ser superior a um indica que as indústrias brasileiras, na média, utilizam mais capital de terceiros do que recursos próprios o que pode ser justificado pela sua baixa lucratividade e pelos incentivos fiscais.

Além disso, a partir de uma análise de regressão linear, foi identificada uma relação negativa entre o grau de endividamento e a rentabilidade no segmento industrial. Isso pode ser um indício de que foi atingido o nível ótimo de endividamento, com um valor próximo a 1,5. Níveis superiores de endividamento não necessariamente irão aumentar o valor da empresa, conforme sugerem alguns autores.

A análise de regressão do ativo total pelo nível de endividamento não indicou relação significativa do ponto de vista estatístico, o que contraria a idéia de que empresas maiores tenderiam a se endividar mais incentivadas por maior disponibilidade de acesso ao crédito.

Finalmente, os setores industriais que têm maior capacidade de crescimento no curto prazo, em função de disponibilidade de captação de recursos, sejam próprios ou de terceiros são os de minerais não metálicos e higiene e limpeza, enquanto o setor de equipamentos de telecomunicações não apresenta bons indicadores em termos de perspectivas de captação de recursos para investimentos.

\section{Referências Bibliográficas}

DE ANGELO, H. e MASULIS, R. (1980) - Optimal Capital Structure Under Corporate and Personal Taxation. Journal of Financial Economics. Vol. 8, n.1, p. 03-29.

EID, W. (1996) - Custo e Estrutura de Capital: O Comportamento das Empresas Brasileiras. Revista de Administração de Empresas. Vol. 36, n. 4, p. 51-59.

FAMÁ, R.; BARROS, L. \& SILVEIRA, A. (2001) - A Estrutura de Capital é Relevante? Novas Evidências a Partir de Dados Norte-Americanos e Latino-Americanos. Caderno de Pesquisas em Administração. Vol. 08, n. 2. São Paulo.

FAMÁ, R. \& GRAVA, J. W. (2000) - Teoria da estrutura de Capital - As Discussões Persistem. Caderno de Pesquisa em Administração. Vol.1, n. 11.

FAMÁ, R. \& MELHER, S. (1999) - Estrutura de Capital na América Latina: Existiria uma Correlação com o Lucro das Empresas? IV SEMEAD - Seminários em Administração. FEA/USP. Mimeo. São Paulo.

GITMAN, L. J. (1997) - Princípios de Administração Financeira. Harbra. $7^{\text {a }}$ Edição. São Paulo.

MARKOWITZ, H. (1952) - Portfolio Selection. The Journal of Finance. P 89.

MODIGLIANI, F. e MILlER, M. H. (1958) - The Cost of Capital, Corporation Finance, and Theory of Investment. American Economic Review. Vol. 48, n. 3, p. 261-297.

MODiGLiANI, F. e MILlER, M. H. (1963) - Corporate Income Taxes and The Cost of Capital: A Correction. American Economic Review. Vol. 53, n. 3, p. 433-443.

MYERS, S. C. \& MAJLUF, N. S.(1984) - Corporate Financing and Investment Decisions When Firms Have Information That Investors do not Have. Journal of Financial Economics. 13 P. 187-221

PROCIANOY, J. L. \& SCHIMITT, F. O. V. (1995) - O Pacote Fiscal de 1995: Estratégias que Otimizam os Recursos dos Investidores. Revista de Administração de Empresas. Vol. 35, n. 5, p. 46-58.

ROSS, S. A.; WESTERFIELD, R. W. \& JAFFE, J. F. (1995) - Administração Financeira. Atlas. São Paulo.

TITMAN, S. \& WESSELS, R. (1988) - The Determinants of Capital Structure Choice. The Journal of Finance. Vol. 431, n. 1. 